\begin{tabular}{|c|c|}
\hline Title & Carbon-Nanotube Growth in A Icohol-V apor Plasma \\
\hline Author(s) & $\begin{array}{l}\text { Suda, Y oshiyuki; Okita, A tsushi; Takay ama, Junichi; Oda, A kinori; Sugawara, Hirotake; Sakai, Y osuke; Oke, } \\
\text { Shinichiro; Takikawa, Hirofumi }\end{array}$ \\
\hline Citation & $\begin{array}{l}\text { IEEE Transactions on Plasma Science, 37(7), 1150-1155 } \\
\text { https://doi.org/10.1109/T PS.2009.2015451 }\end{array}$ \\
\hline Issue Date & $2009-07$ \\
\hline Doc URL & http:/hdl .handle.net $/ 2115 / 38853$ \\
\hline Rights & $\begin{array}{l}\text { ( ) } 2009 \text { IEEE. Personal use of this material is permitted. However, permission to reprint/republish this material for } \\
\text { advertising or promotional purposes or for creating new collective works for resale or redistribution to servers or lists, } \\
\text { or to reuse any copyrighted component of this work in other works must be obtained from the IEEE. }\end{array}$ \\
\hline Type & article \\
\hline File Information & Y_Suda IEEE-TPS-37-2009-1150.pdf \\
\hline
\end{tabular}

Instructions for use 


\title{
Carbon-Nanotube Growth in Alcohol-Vapor Plasma
}

\author{
Yoshiyuki Suda, Atsushi Okita, Junichi Takayama, Akinori Oda, Hirotake Sugawara, \\ Yosuke Sakai, Shinichiro Oke, and Hirofumi Takikawa, Member, IEEE
}

\begin{abstract}
We have successfully grown carbon nanotubes (CNTs) by plasma-enhanced chemical vapor deposition (PECVD) using alcohol. When 0.01-wt \% ferrocene was added to the alcohol, vertically aligned CNTs grew at $650{ }^{\circ} \mathrm{C}$. By contrast, a few CNTs and mostly carbon nanoparticles were obtained by pure alcohol PECVD even though the Fe catalyst was coated on Si substrates. Comparing this PECVD experiment with thermal alcohol CVD showed that only the PECVD method can be used to grow CNTs under the reported experimental conditions. To understand the plasma properties for CNT growth, particularly plasma species contained in a gas phase of alcohol plasma, the plasma was analyzed using optical-emission spectroscopy (OES) and quadrupole mass spectrometry (QMS). From the OES measurement, emission peaks from the excitation states of $\mathrm{C}_{2}, \mathrm{CH}, \mathrm{CHO}, \mathrm{CH}_{2} \mathrm{O}, \mathrm{CO}, \mathrm{H}$, $\mathrm{O}_{2}, \mathrm{C}^{+}$, and $\mathrm{CO}^{+}$were identified, while the QMS measurement also showed the existence of $\mathrm{H}_{2}, \mathrm{O}$, and $\mathrm{CO}$. These results indicate that, in alcohol plasma, oxidants and reductants exist together and potentially promote/suppress CNT growth depending on the process conditions. The contribution of $\mathrm{C}_{x} \mathrm{H}_{y}(x \geq 1, y \geq 3)$ radicals, which were produced by decomposition reactions in alcohol plasma as a CNT precursor, is discussed.
\end{abstract}

Index Terms-Carbon nanotube (CNT), ferrocene, mass spectrometry, optical-emission spectroscopy (OES), plasma-enhanced chemical vapor deposition (PECVD).

\section{INTRODUCTION}

C ARBON nanotubes (CNTs) have attracted significant interest due to their unique properties, e.g., high chemical stability, mechanical strength, and current density. Based on these properties, our group has focused on the application of CNTs as nanoscale interconnections in large-scale integrated (LSI) circuits [1], [2]. Plasma-enhanced chemical vapor deposition (PECVD) is superior to other techniques including arc discharge, laser ablation, and CVD for the low-temperature operation of CNT growth $\left(\sim 390{ }^{\circ} \mathrm{C}\right)$. The PECVD approach meets the condition for the LSI fabrication process $\left(\leq 400{ }^{\circ} \mathrm{C}\right)$

Manuscript received October 3, 2008; revised January 17, 2009. First published April 3, 2009; current version published July 9, 2009.

Y. Suda was with the Graduate School of Information Science and Technology, Hokkaido University, Sapporo 060-0814, Japan. He is now with the Department of Electrical and Electronic Engineering, Toyohashi University of Technology, Toyohashi 441-8580, Japan (e-mail: suda@eee.tut.ac.jp).

A. Okita was with the Graduate School of Information Science and Technology, Hokkaido University, Sapporo 060-0814, Japan. He is now with Hitachi High-Technologies Corporation, Hitachinaka 312-8504, Japan.

J. Takayama, H. Sugawara, and Y. Sakai are with the Graduate School of Information Science and Technology, Hokkaido University, Sapporo 060-0814, Japan.

A. Oda is with the Department of Engineering Physics, Electronics and Mechanics, Graduate School of Engineering, Nagoya Institute of Technology, Nagoya 466-8555, Japan.

S. Oke and H. Takikawa are with the Department of Electrical and Electronic Engineering, Toyohashi University of Technology, Toyohashi 441-8580, Japan.

Color versions of one or more of the figures in this paper are available online at http://ieeexplore.ieee.org.

Digital Object Identifier 10.1109/TPS.2009.2015451
[3]. By contrast, recent reports of CVD growth using $\mathrm{O}_{2}$ gas [4] and water vapor [5] as an additive to $\mathrm{CH}_{4}$ and $\mathrm{C}_{2} \mathrm{H}_{4}$, respectively, provide an enormous advantage in long CNT growth with high yields. These oxidants are thought to play a role in activating catalyst particles for long lifetimes and, thereby, allowing the growth of longer CNTs. Alcohol is also well known to grow high-purity CNTs; Maruyama et al. [6] discussed the role of decomposed $\mathrm{OH}$ radicals from alcohol for the efficient removal of amorphous carbon during $\mathrm{CNT}$ growth.

Our group has studied the PECVD of CNTs using $\mathrm{CH}_{4} / \mathrm{H}_{2}$ gas mixtures and the correlation among reactions in the plasma gas phase, the state of the catalyst nanoparticles, and the CNT growth conditions [7]-[10]. We have developed a $\mathrm{CH}_{4} / \mathrm{H}_{2}$ simulation code and have paid close attention to the supply of a carbon source as a precursor for CNTs. To simulate the CNTgrowth process, surface chemistry including surface activation and chemical sputtering are necessary [11]. By considering the sticking probabilities of ions and radicals, we estimated the total amount of carbon atoms supplied from the plasma onto the catalyst surface. In our analysis, it was concluded that the $\mathrm{C}_{2} \mathrm{H}_{5}^{+}$ion and neutral species $\left(\mathrm{C}_{x} \mathrm{H}_{y} ; x, y>2\right)$ are the main precursors for CNT growth [7], [8], [10].

In this paper, we report the use of a new carbon source, alcohol $\left(\mathrm{C}_{2} \mathrm{H}_{5} \mathrm{OH}\right)$, in PECVD for CNT growth and the analysis of the source's plasma. In this plasma, CNTs can be grown under limited conditions (pressure $=133 \mathrm{~Pa}$, input power $=200 \mathrm{~W}$, temperature $=650{ }^{\circ} \mathrm{C}, \mathrm{Fe}$ catalysts with $\mathrm{Al}_{2} \mathrm{O}_{3}$ supports). PECVD of CNTs using $\mathrm{C}_{2} \mathrm{H}_{5} \mathrm{OH}$ has been reported [12], [13], but various species, including hydrocarbon radicals, ions, oxidants, and reductants, are present in $\mathrm{C}_{2} \mathrm{H}_{5} \mathrm{OH}$ plasma, and the properties of these species remain unclear. Clearly, it is important to understand the characteristics of the plasma species in $\mathrm{C}_{2} \mathrm{H}_{5} \mathrm{OH}$ plasma and to investigate the contribution of these species to CNT growth. In this paper, we measured the plasma optical emissions by optical-emission spectroscopy (OES) and investigated the existence of plasma species by quadrupole mass spectrometry (QMS). The $\mathrm{C}_{2} \mathrm{H}_{5} \mathrm{OH}$ plasma species monitored by OES and QMS is presented.

\section{EXPERIMENTAL SETUP}

Fig. 1 shows the experimental setup for alcohol PECVD. The details of the experimental setup and CNT growth procedure are described in earlier reports [7]-[9]. The ribbon heater was equipped to provide a stable alcohol-vapor feed. To compare CNT growth, pure $\mathrm{C}_{2} \mathrm{H}_{5} \mathrm{OH}$ and $\mathrm{C}_{2} \mathrm{H}_{5} \mathrm{OH}$ containing 0.01-wt $\%$ ferrocene $\left(\mathrm{C}_{10} \mathrm{H}_{10} \mathrm{Fe}\right)$ were used. We prepared the catalyst/support materials on a Si substrate using the electronbeam (EB)-evaporation approach. The substrates used were $\mathrm{Si}$ 


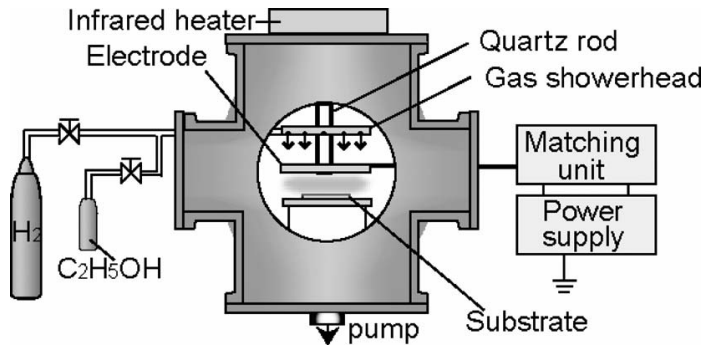

Fig. 1. Experimental apparatus for alcohol plasma-enhanced CVD.

TABLE I

EXPERIMENTAL CONDITIONS

\begin{tabular}{|c|c|c|}
\hline & Pretreatment condition & Process condition \\
\hline Gas & $\mathrm{H}_{2}$ & $\mathrm{C}_{2} \mathrm{H}_{5} \mathrm{OH}$ vapor \\
& $($ Gas flow rate $=50$ & $(+0.01-\mathrm{wt} \%$ Ferrocene $)$ \\
\hline Pressure & $666 \mathrm{~Pa}$ & $133 \mathrm{~Pa}$ \\
\hline Process & $550^{\circ} \mathrm{C}$ & $650{ }^{\circ} \mathrm{C}$ \\
temperature & & $200 \mathrm{~W}$ \\
\hline RF input power & $50 \mathrm{~W}$ & $10 \mathrm{~min}$ \\
\hline Process time & $4 \mathrm{~min}$ & \\
\hline
\end{tabular}

wafers with a 20-nm-thick $\mathrm{SiO}_{2}$ layer. In the EB evaporation, the $\mathrm{Fe}$ (catalyst) and $\mathrm{Al}_{2} \mathrm{O}_{3}$ (support) were deposited on the substrates to form sandwichlike structures $\left(\mathrm{Al}_{2} \mathrm{O}_{3} / \mathrm{Fe} /\right.$ $\mathrm{Al}_{2} \mathrm{O}_{3}=1 / 1 / 1 \mathrm{~nm}$ ), which can then form small nanoparticles [9], [14]. The pretreatment and growth conditions including pressure, power, process temperature, and process time are listed in Table I.

The procedure of CNT growth is briefly described. First, substrates with catalyst and support materials were set on the center of the grounded electrode. The reactor was pumped down to below $10^{-4} \mathrm{~Pa}$. Using an infrared heater, the substrates were heated and kept at $550{ }^{\circ} \mathrm{C}$ in $666-\mathrm{Pa} \mathrm{H}_{2}$ plasma for 4 min. The $\mathrm{H}_{2}$ gas was removed, and $\mathrm{C}_{2} \mathrm{H}_{5} \mathrm{OH}$ (water content $\leq 0.2 \%$, with/without 0.01 -wt $\%$ ferrocene) was introduced. The pressure was maintained at $133 \mathrm{~Pa}$, while the temperature was maintained at $650{ }^{\circ} \mathrm{C}$ for $10 \mathrm{~min}$. During CNT growth by PECVD, plasma optical-emission spectra were acquired using a photonic multichannel analyzer (PMA: Hamamatsu Photonics K.K., PMA-11) in the wavelength range of 300-800 nm. A quadrupole mass spectrometer (QMS: ANELVA, M-QA200TS) was used to analyze the plasma species. The QMS tube was connected with the PECVD chamber through a 50-cm-long 1/8-in-diameter stainless-steel pipe and a variable leak valve. Pressure inside the QMS tube was carefully controlled by the valve, and the QMS spectra of $\mathrm{CH}_{4} / \mathrm{H}_{2}$ gas with/without plasma were evaluated. The CNTs obtained were characterized using a scanning electron microscope (SEM: Hitachi HighTechnologies Corporation, S-4800) and a transmission electron microscope (TEM: JEOL, 2000FX).
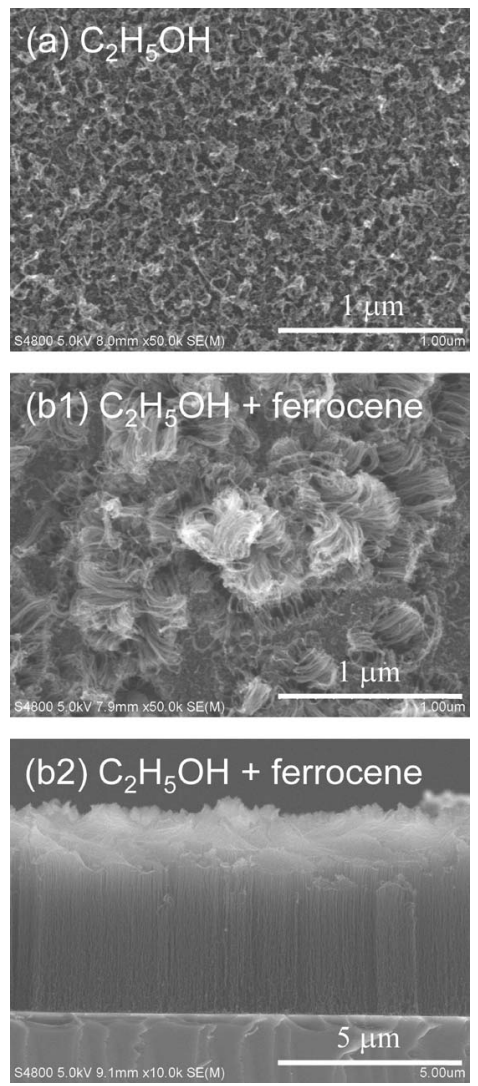

Fig. 2. SEM micrographs of CNTs obtained using a $133-\mathrm{Pa} \mathrm{C}_{2} \mathrm{H}_{5} \mathrm{OH}$ plasma. $\mathrm{Al}_{2} \mathrm{O}_{3} / \mathrm{Fe} / \mathrm{Al}_{2} \mathrm{O}_{3}[=1 / 1 / 1 \mathrm{~nm}$, (a), and (b)] is used for the catalyst/support materials. Ferrocene is mixed with $\mathrm{C}_{2} \mathrm{H}_{5} \mathrm{OH}$, and the growth results are shown in (b). (b2) is the cross-sectional view of (b1), which confirms the formation of vertically aligned CNTs.

\section{Results AND Discussion}

Fig. 2 shows the CNT growth results obtained using $\mathrm{C}_{2} \mathrm{H}_{5} \mathrm{OH}$ plasma. The substrate with $\mathrm{Al}_{2} \mathrm{O}_{3} / \mathrm{Fe} / \mathrm{Al}_{2} \mathrm{O}_{3}$ showed CNT growth over the whole substrate area, resulting in a high production yield of CNTs. The effect of adding ferrocene can be clearly seen. As shown in Fig. 2(b2), vertically aligned CNTs were obtained when ferrocene was added, although Fig. 2(b1) and (b2) revealed that CNT growth occurred over the whole substrate area. To confirm the effect of the $\mathrm{Al}_{2} \mathrm{O}_{3} / \mathrm{Fe} / \mathrm{Al}_{2} \mathrm{O}_{3}$ catalysts, we observed the CNT deposition on a Si substrate. Without catalyst, no CNTs were obtained on a $\mathrm{Si}$ substrate even though ferrocene was supplied with the alcohol. This clearly indicated that a carbon source containing a ferrocene molecule can be activated on the catalyst surface and used to grow CNTs. Eres et al. [15] used a substrate that was catalyzed using a $\mathrm{Mo} / \mathrm{Fe} / \mathrm{Al}$ multilayer and found that the introduction of ferrocene into the acetylene-gas stream enhanced the growth of vertically aligned CNTs. In addition, CNT growth has been achieved using ferrocene-containing ethanol solutions in spray pyrolysis [12] and inductively coupled plasma [13] techniques. However, the concentrations of ferrocene in these reports (i.e., $1000 \mathrm{mg} / 100-800 \mathrm{~mL}$ by Su et al. [12] and $5 \mathrm{mg} / 10 \mathrm{~mL}$ by Xu et al. [13]) are higher than the levels used in our experiment $(8 \mathrm{mg} / 100 \mathrm{~mL})$. TEM analysis showed the effect of the addition of ferrocene (Fig. 3). In the absence of ferrocene, a large 

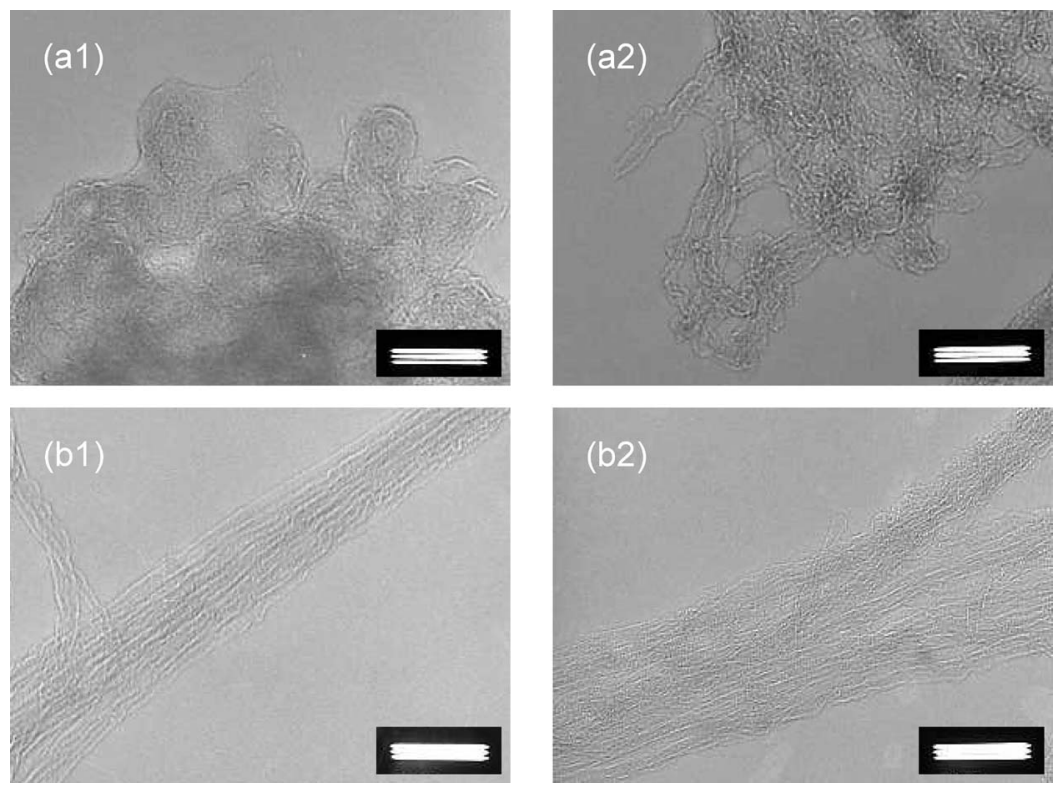

Fig. 3. TEM micrographs of carbon deposits grown from (a) $\mathrm{C}_{2} \mathrm{H}_{5} \mathrm{OH}$ only and (b) $\mathrm{C}_{2} \mathrm{H}_{5} \mathrm{OH}$ with ferrocene. Scale bar $=50 \mathrm{~nm}$.

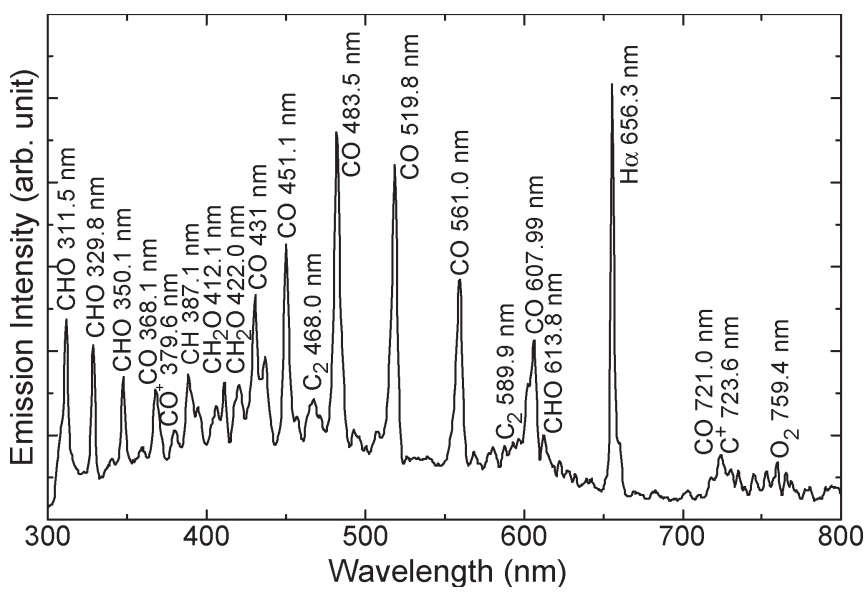

Fig. 4. Optical-emission spectra of $\mathrm{C}_{2} \mathrm{H}_{5} \mathrm{OH}$ plasma at $133 \mathrm{~Pa}$.

number of carbon nanoparticles and nanocapsules were formed on the $\mathrm{Al}_{2} \mathrm{O}_{3} / \mathrm{Fe} / \mathrm{Al}_{2} \mathrm{O}_{3}$-catalyzed substrate. By contrast, a bundle structure composed of CNTs with a diameter of $\sim 5 \mathrm{~nm}$ was formed by the ferrocene-assisted reaction.

To ensure the effect of plasma, we confirmed that no CNTs were obtained at a substrate temperature of $650{ }^{\circ} \mathrm{C}$ without plasma. Chiashi et al. [16] who performed single-walled CNT (SWCNT) growth in a cold-wall CVD reported that the effective reaction temperature of alcohol CVD was estimated to be slightly higher than $850^{\circ} \mathrm{C}$, whereas a low-temperature reaction caused the generation of amorphous carbon.

Fig. 4 shows the OES spectra obtained using a 133-Pa $\mathrm{C}_{2} \mathrm{H}_{5} \mathrm{OH}$ plasma. The measurements were performed at room temperature to avoid the detection of light from the heating system. As a result of this OES measurement, optical peaks from $\mathrm{C}_{2}, \mathrm{CH}, \mathrm{CHO}, \mathrm{CH}_{2} \mathrm{O}, \mathrm{CO}, \mathrm{H}_{\alpha}$ ( $\mathrm{H}$ atom in the Balmer series), $\mathrm{O}_{2}, \mathrm{C}^{+}$, and $\mathrm{CO}^{+}$were identified. Fig. 5(a) shows the QMS result obtained using a 133- $\mathrm{Pa}_{2} \mathrm{H}_{5} \mathrm{OH}$ plasma. From the QMS analysis, peaks corresponding to each molecular weight were observed: $\mathrm{H}_{2}$ (between 1 and 3), $\mathrm{CH}_{4}$ (between 12 and 18), $\mathrm{CH}_{3} \mathrm{OH}$ (between 24 and 31), and $\mathrm{C}_{2} \mathrm{H}_{5} \mathrm{OH}$ (between 38 and 46). Since the ionization process of particles by electron collision is absolutely necessary for QMS detection, the decomposition of the $\mathrm{C}_{2} \mathrm{H}_{5} \mathrm{OH}$ molecule occurs. We measured the QMS peaks obtained in the 133- $\mathrm{Pa} \mathrm{C}_{2} \mathrm{H}_{5} \mathrm{OH}$ atmosphere [without plasma, Fig. 5(b)]. Fig. 5(c) shows the subtraction of the spectral intensity of plasma-off [Fig. 5(b)] from that of plasmaon [Fig. 5(a)]. The result indicates that the peaks of $\mathrm{C}_{2} \mathrm{H}_{5} \mathrm{OH}-$ derived molecules $\left(\mathrm{CH}_{4}, \mathrm{CH}_{3} \mathrm{OH}\right.$, and $\left.\mathrm{C}_{2} \mathrm{H}_{5} \mathrm{OH}\right)$ decreased by igniting the plasma. This shows that the decomposition of $\mathrm{C}_{2} \mathrm{H}_{5} \mathrm{OH}$ is promoted by generating plasma. By contrast, the species of $\mathrm{H}_{2}, \mathrm{O}, \mathrm{CO}$, and $\mathrm{C}_{2} \mathrm{H}_{4}$ (atomic/molecular weight $=$ $2,16,28$, and 28 , respectively) increased by the recombination/dissociation processes. These results reflect the observation that plasma processes can promote the production of several species by plasma reactions.

In this paper, we discuss the decomposition/dissociation reactions of $\mathrm{C}_{2} \mathrm{H}_{5} \mathrm{OH}$ plasma. Several groups [17]-[21] have reported the chemical-reaction processes of $\mathrm{C}_{2} \mathrm{H}_{5} \mathrm{OH}$ plasma.

$$
\begin{aligned}
& \mathrm{C}_{2} \mathrm{H}_{5} \mathrm{OH} \rightarrow \mathrm{C}+\mathrm{CO}+3 \mathrm{H}_{2} \\
& \mathrm{C}_{2} \mathrm{H}_{5} \mathrm{OH}+3 \mathrm{H}_{2} \mathrm{O} \rightarrow 2 \mathrm{CO}_{2}+6 \mathrm{H}_{2} \\
& \mathrm{C}_{2} \mathrm{H}_{5} \mathrm{OH}+\mathrm{H}_{2} \mathrm{O} \rightarrow 2 \mathrm{CO}+4 \mathrm{H}_{2} \\
& \mathrm{C}_{2} \mathrm{H}_{5} \mathrm{OH} \rightarrow \mathrm{C}_{2} \mathrm{H}_{4}+\mathrm{H}_{2} \mathrm{O} \\
& \mathrm{C}_{2} \mathrm{H}_{5} \mathrm{OH} \rightarrow \mathrm{C}_{2} \mathrm{H}_{5}+\mathrm{OH} .
\end{aligned}
$$

Reaction (1) is a collision-impact process between electrons and radicals in plasma [17] as well as a typical reaction occurring on a catalyst surface for CNTs growth by nonplasma alcohol CVD. However, the CNT formation in this experiment could not be explained simply by this reaction, since no carbon 

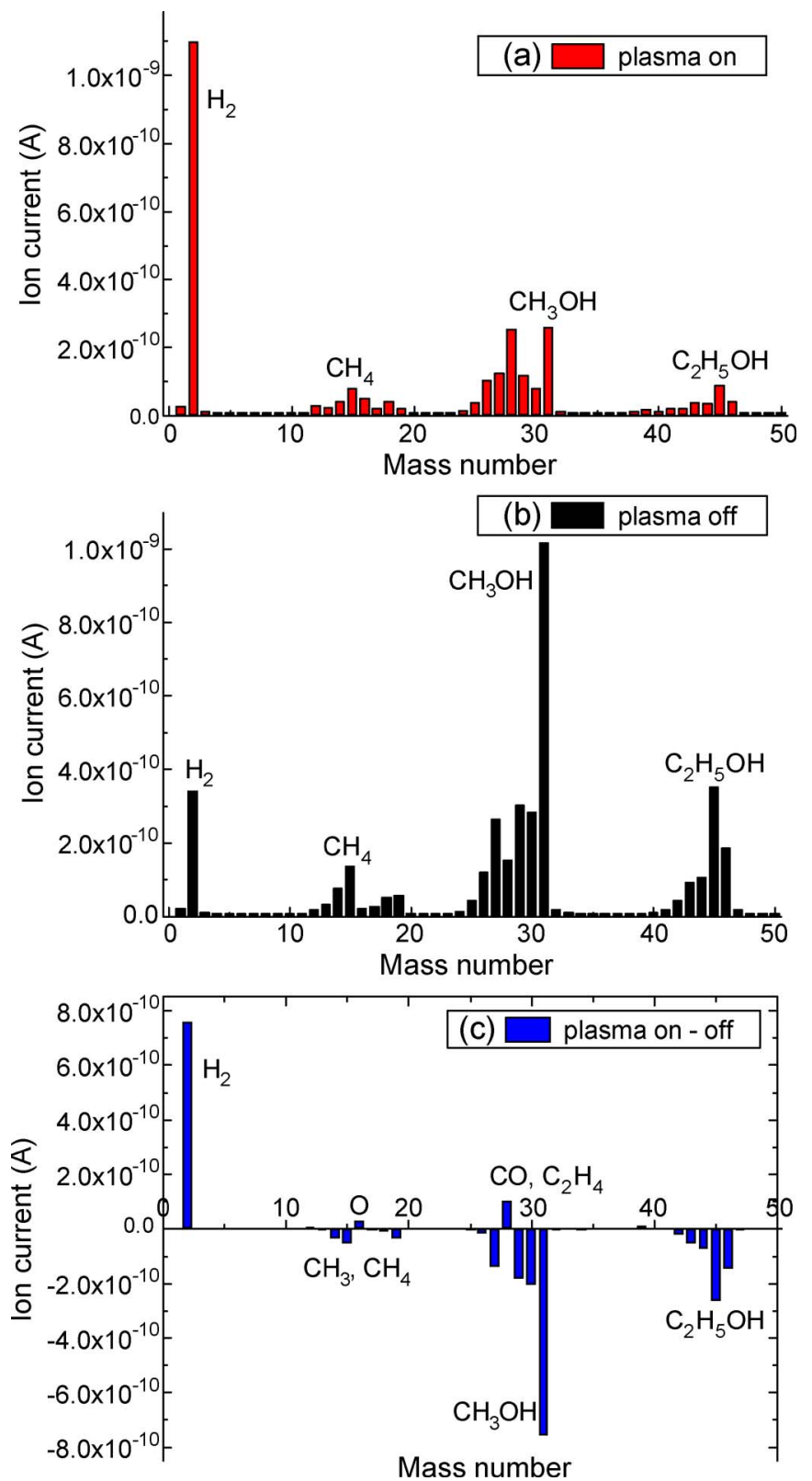

Fig. 5. Mass spectra obtained by (a) $\mathrm{C}_{2} \mathrm{H}_{5} \mathrm{OH}$ PECVD and (b) $\mathrm{C}_{2} \mathrm{H}_{5} \mathrm{OH}$ vapor (without plasma) at $133 \mathrm{~Pa}$. (c) Subtraction of (b) from (a).

deposit was observed without plasma. Generation of $\mathrm{CO}, \mathrm{CO}_{2}$, and $\mathrm{H}_{2}$ as proposed by reactions (1)-(5) is consistent with the presented OES and QMS analyses. A small amount of $\mathrm{H}_{2} \mathrm{O}$ $(\leq 0.2 \%)$ was present in the ethanol used, and therefore, reactions (2) and (3) take place. Considering the dissociation energies by electron collision of $\mathrm{CO}, \mathrm{CO}_{2}, \mathrm{OH}, \mathrm{H}_{2}$, and $\mathrm{H}_{2} \mathrm{O}$, namely, 11.09, 5.2, 4.39, 8.8, and $7.0 \mathrm{eV}$, respectively [17], [22]-[25], it was observed that these species were easily dissociated in the plasma and possibly adsorb onto the catalyst surface. This could explain the requirement of ferrocene for CNT growth.

$\mathrm{CO}_{2}, \mathrm{H}_{2} \mathrm{O}$, and $\mathrm{OH}$, which work as oxidants, and $\mathrm{CO}$ and $\mathrm{H}_{2}$, which operate as reductants, are simultaneously produced in the gas phase through reactions (1)-(5). Several papers describe their effects on CNT growth, e.g., supergrowth of SWCNTs by the addition of a small amount of $\mathrm{H}_{2} \mathrm{O}(175 \mathrm{ppm})$ in the carbon source $\left(\mathrm{C}_{2} \mathrm{H}_{4}\right)$ [5], the oxidation of the catalyst by existing $\mathrm{OH}$ radicals [6], and the optimization of the carbon/hydrogen ratio by $\mathrm{O}$ atoms [4]. Among the aforementioned molecules $\left(\mathrm{CO}_{2}\right.$, $\mathrm{H}_{2} \mathrm{O}, \mathrm{OH}, \mathrm{CO}$, and $\mathrm{H}_{2}$ ), only $\mathrm{CO}$ can be used as a carbon source for CNT by a CO disproportionation reaction below $900{ }^{\circ} \mathrm{C}$ [26]. These species produced in the plasma have a strong influence on the catalyst state and CNT growth by varying their concentration in the gas phase.

A recent experiment by Oshima et al. [27] showed that $\mathrm{C}_{2} \mathrm{H}_{5} \mathrm{OH}$ thermally decomposed at $840{ }^{\circ} \mathrm{C}$ without plasma and a metal catalyst, and $\mathrm{C}_{2} \mathrm{H}_{4}, \mathrm{C}_{2} \mathrm{H}_{2}, \mathrm{C}_{2} \mathrm{H}_{4} \mathrm{O}, \mathrm{CH}_{4}, \mathrm{CO}, \mathrm{CO}_{2}$, and $\mathrm{H}_{2} \mathrm{O}$ were generated through the thermal reactions. This paper suggested that hydrocarbons such as $\mathrm{C}_{2} \mathrm{H}_{4}$ and $\mathrm{C}_{2} \mathrm{H}_{2}$ can be used as a CNT precursor. Our previous work using $\mathrm{CH}_{4} / \mathrm{H}_{2}$ plasma concluded that $\mathrm{C}_{2} \mathrm{H}_{5}^{+}$and $\mathrm{C}_{x} \mathrm{H}_{y}(x, y \geq 2)$ are the main precursors [7], [8], [10] and that $\mathrm{Al}_{2} \mathrm{O}_{3} / \mathrm{Fe} / \mathrm{Al}_{2} \mathrm{O}_{3}$ catalyst resulted in high yields of CNTs. According to the present QMS measurement, the radicals derived from the $\mathrm{C}_{2} \mathrm{H}_{5} \mathrm{OH}$ molecule are the major species in the plasma. The species observed by QMS are different from those by OES because the emission peaks of hydrocarbon radicals are located in the infrared region and outside the measurement range. Considering these results, we speculate that $\mathrm{C}_{2} \mathrm{H}_{4}$ and $\mathrm{C}_{2} \mathrm{H}_{5}$ which were generated by electron impact collision with $\mathrm{C}_{2} \mathrm{H}_{5} \mathrm{OH}$ would be CNT precursors in this system. Since the molecular weight of $\mathrm{CO}$ and $\mathrm{C}_{2} \mathrm{H}_{4}$ are equivalent, it is difficult to distinguish between these two species [Fig. 5(c)]. The presence of $\mathrm{CO}$ indicates that carbon is provided by the $\mathrm{CO}$ disproportionation reaction [26]. By employing plasma, the electron-collision process in the plasma reduces the effective temperature for CNT growth by approximately $200{ }^{\circ} \mathrm{C}$, when compared with the nonplasma CVD process [27].

\section{CONCLUSION}

In this paper, we reported multiwalled CNT growth by alcohol PECVD at $650{ }^{\circ} \mathrm{C}$. By adding 0.01-wt $\%$ ferrocene in $\mathrm{C}_{2} \mathrm{H}_{5} \mathrm{OH}$, the yield of CNTs increased, and well-aligned CNTs were grown on an $\mathrm{Al}_{2} \mathrm{O}_{3} / \mathrm{Fe} / \mathrm{Al}_{2} \mathrm{O}_{3}$ substrate. Using plasma OES, the spectral peaks from the resulting atoms and molecules $\left(\mathrm{C}_{2}, \mathrm{CH}, \mathrm{CHO}, \mathrm{CH}_{2} \mathrm{O}, \mathrm{CO}, \mathrm{H}, \mathrm{O}_{2}, \mathrm{C}^{+}\right.$, and $\left.\mathrm{CO}^{+}\right)$ were identified. In the QMS measurement, the peaks of $\mathrm{H}_{2}$, $\mathrm{CH}_{4}, \mathrm{CH}_{3} \mathrm{OH}$, and $\mathrm{C}_{2} \mathrm{H}_{5} \mathrm{OH}$ were detected, and a decrease in intensity of $\mathrm{CH}_{4}, \mathrm{CH}_{3} \mathrm{OH}$, and $\mathrm{C}_{2} \mathrm{H}_{5} \mathrm{OH}$ by generating plasma was shown. By utilizing the plasma dissociation process for alcohol, oxidants (such as $\mathrm{CO}_{2}, \mathrm{H}_{2} \mathrm{O}, \mathrm{OH}$ ) and reductants $\left(\mathrm{CO}, \mathrm{H}_{2}\right)$, as well as $\mathrm{C}_{x} \mathrm{H}_{y}(x \geq 1, y \geq 3)$ that are precursors for CNT growth, can be effectively produced at a lower temperature in plasma.

\section{ACKNOWLEDGMENT}

The authors would like to thank M. Maekawa, Y. Hizume, N. Asaoka, and Y. Fukuda of Hokkaido University for their helpful discussions and comments. Y. Suda and A. Okita would also like to acknowledge the JSPS for their research support. 


\section{REFERENCES}

[1] F. Kreupl, A. P. Graham, G. S. Duesberg, W. Steinhogl, M. Liebau, E. Unger, and W. Honlein, "Carbon nanotubes in interconnect applications," Microelectron. Eng., vol. 64, no. 1, pp. 399-408, Oct. 2002.

[2] N. R. Franklin and H. Dai, "An enhanced CVD approach to extensive nanotube networks with directionality," Adv. Mater, vol. 12, no. 12, pp. 890-894, 2000.

[3] D. Yokoyama, T. Iwasaki, T. Yoshida, H. Kawarada, S. Sato, T. Hyakushima, M. Nihei, and Y. Awano, "Low temperature grown carbon nanotube interconnects using inner shells by chemical mechanical polishing," Appl. Phys. Lett., vol. 91, no. 26, p. 263 101, Dec. 2007.

[4] G. Zhang, D. Mann, L. Zhang, A. Javey, Y. Li, E. Yenilmez, Q. Wang, J. P. McVittie, Y. Nishi, J. Gibbons, and H. Dai, "Ultra-high-yield growth of vertical single-walled carbon nanotubes: Hidden roles of hydrogen and oxygen," Proc. Nat. Acad. Sci., vol. 102, no. 45, pp. 16 141-16 145, 2005.

[5] K. Hata, D. N. Futaba, K. Mizuno, T. Namai, M. Yumura, and S. Iijima, "Water-assisted highly efficient synthesis of impurity-free single-walled carbon nanotubes," Science, vol. 306, no. 5700, pp. 1362 1364, Nov. 2004.

[6] S. Maruyama, R. Kojima, Y. Miyauchi, S. Chiashi, and M. Kohno, "Lowtemperature synthesis of high-purity single-walled carbon nanotubes from alcohol," Chem. Phys. Lett., vol. 360, no. 3/4, pp. 229-234, 2002.

[7] A. Okita, Y. Suda, A. Ozeki, H. Sugawara, Y. Sakai, A. Oda, and J. Nakamura, "Predicting the amount of carbon in carbon nanotubes grown by $\mathrm{CH}_{4}$ rf plasmas," J. Appl. Phys., vol. 99, no. 1, p. 014302 , 2006.

[8] A. Okita, Y. Suda, A. Oda, J. Nakamura, A. Ozeki, K. Bhattacharyya, H. Sugawara, and Y. Sakai, "Effects of hydrogen on carbon nanotube formation in $\mathrm{CH}_{4} / \mathrm{H}_{2}$ plasmas," Carbon, vol. 45, no. 7, pp. 1518-1526, Jun. 2007.

[9] A. Okita, A. Ozeki, Y. Suda, J. Nakamura, A. Oda, K. Bhattacharyya, H. Sugawara, and Y. Sakai, "Analysis of oxidation state of multilayered catalyst thin films for carbon nanotube growth using plasma-enhanced chemical vapor deposition," Jpn. J. Appl. Phys., vol. 45, no. 10B, pp. 8323-8329, 2006.

[10] A. Oda, Y. Suda, and A. Okita, "Numerical analysis of pressure dependence on carbon nanotube growth in $\mathrm{CH}_{4} / \mathrm{H}_{2}$ plasmas," Thin Solid Films, vol. 516, no. 19, pp. 6570-6574, Aug. 2008.

[11] C. Hopf, W. Jacob, and A. von Keudell, "Ion-induced surface activation, chemical sputtering, and hydrogen release during plasma-assisted hydrocarbon film growth," J. Appl. Phys., vol. 97, no. 9, p. 094 904, 2005.

[12] L. F. Su, J. N. Wang, F. Yu, Z. M. Sheng, H. Chang, and C. Pak, "Continuous production of single-wall carbon nanotubes by spray pyrolysis of alcohol with dissolved ferrocene," Chem. Phys. Lett., vol. 420, no. 4/6, pp. 421-425, Mar. 2006

[13] B. Xu, T. Li, X. Liu, X. Lin, and J. Li, "Growth of well-aligned carbon nanotubes in a plasma system using ferrocene solution in ethanol," Thin Solid Films, vol. 515, no. 17, pp. 6726-6729, 2007.

[14] G. Zhong, T. Iwasaki, K. Honda, Y. Furukawa, I. Ohdomari, and H. Kawarada, "Very high yield growth of vertically aligned single-walled carbon nanotubes by point-arc microwave plasma CVD," Chem. Vap. Depos., vol. 11, no. 3, pp. 127-130, 2005.

[15] G. Eres, A. A. Puretzky, D. B. Geohegan, and H. Cui, "In situ control of the catalyst efficiency in chemical vapor deposition of vertically aligned carbon nanotubes on predeposited metal catalyst films," Appl. Phys. Lett., vol. 84, no. 10, pp. 1759-1761, 2004.

[16] S. Chiashi, Y. Murakami, Y. Miyauchi, and S. Maruyama, "Cold wall CVD generation of single-walled carbon nanotubes and in situ Raman scattering measurements of the growth stage," Chem. Phys. Lett., vol. 386, no. 1-3, pp. 89-94, Mar. 2004.

[17] A. Yanguas-Gil, J. L. Hueso, J. Cotrino, A. Caballero, and A. R. GonzalezElipe, "Reforming of ethanol in a microwave surface-wave plasma discharge," Appl. Phys. Lett., vol. 85, no. 18, pp. 4004-4006, 2004.

[18] O. Aubry, C. Met, A. Khacef, and J. M. Cormier, "On the use of a non-thermal plasma reactor for ethanol steam reforming," Chem. Eng. J., vol. 106, no. 3, pp. 241-247, 2005.

[19] E. L. Izake, T. Paulmier, J. M. Bell, and P. M. Fredericks, "Characterization of reaction products and mechanisms in atmospheric pressure plasma deposition of carbon films from ethanol," J. Mater. Chem., vol. 15, no. 2, pp. 300-306, 2005.

[20] J. Park, R. S. Zhu, and M. C. Lin, "Thermal decomposition of ethanol. I. Ab Initio molecular orbital/Rice-Ramsperger-Kassel-Marcus prediction of rate constant and product branching ratios," J. Chem. Phys., vol. 117, no. 7, pp. 3224-3231, 2002.

[21] NIST Chemical Kinetics Database. [Online]. Available: http://kinetics. nist.gov/kinetics/
[22] A. M. Efremov, G. H. Kim, D. I. Balashov, and C. I. Kim, "Plasma parameters and chemical kinetics of an $\mathrm{HCl}$ DC glow discharge," Vacuum, vol. 81, no. 3, pp. 244-250, Oct. 2006.

[23] S. L. Brock, M. Marquez, S. L. Suib, Y. Hayashi, and H. Matsumoto, "Plasma decomposition of $\mathrm{CO}_{2}$ in the presence of metal catalysts," J. Catal., vol. 180, no. 2, pp. 225-233, Dec. 1998.

[24] T. Harb, W. Kedzierski, and J. W. McConkey, "Production of ground state $\mathrm{OH}$ following electron impact on $\mathrm{H}_{2} \mathrm{O}$," J. Chem. Phys., vol. 115, no. 12, pp. 5507-5512, 2001

[25] Y. Itikawa and N. Mason, "Cross sections for electron collisions with water molecules," J. Phys. Chem. Ref. Data, vol. 34, no. 1, pp. 1-22, 2005.

[26] A. G. Nasibulin, D. P. Brown, P. Queipo, D. Gonzalez, H. Jiang, and E. I. Kauppinen, "An essential role of $\mathrm{CO}_{2}$ and $\mathrm{H}_{2} \mathrm{O}$ during single-walled CNT synthesis from carbon monoxide," Chem. Phys. Lett., vol. 417, no. 1-3, pp. 179-184, 2006.

[27] H. Oshima, Y. Suzuki, T. Shimazu, and S. Maruyama, "Novel and simple synthesis method for submillimeter long vertically aligned single-walled carbon nanotubes by no-flow alcohol catalytic chemical vapor deposition,” Jpn. J. Appl. Phys., vol. 47, no. 4, pp. 1982-1984, 2008.

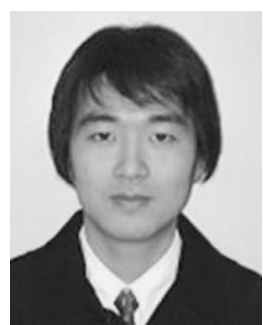

Yoshiyuki Suda was born in Japan in 1971. He received the M.E. and Ph.D. degrees in electronic information engineering from the Graduate School of Information Science and Technology, Hokkaido University, Sapporo, Japan, in 1997 and 2006, respectively.

From 2004 to 2007, he was a Research Associate with the Graduate School of Information Science and Technology, Hokkaido University, where he was an Assistant Professor in 2007. He is currently an Associate Professor with the Department of Electrical and Electronic Engineering, Toyohashi University of Technology, Toyohashi, Japan.

Dr. Suda is a member of the IEE of Japan, Japan Society of Applied Physics, and Fullerenes and Nanotubes Research Society.

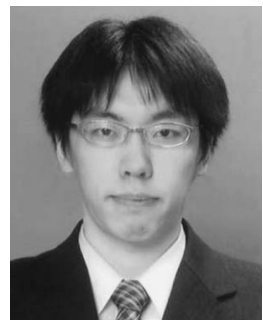

Atsushi Okita was born in Japan in 1980. He received the B.Eng. degree from Muroran Institute of Technology, Muroran, Japan, in 2003 and the M.Eng. and D.Eng. degrees from the Graduate School of Information Science and Technology, Hokkaido University, Sapporo, Japan, in 2005 and 2008, respectively.

He was a Research Fellow of the Japan Society for the Promotion of Science. He is currently with Hitachi High-Technologies Corporation, Hitachinaka, Japan.

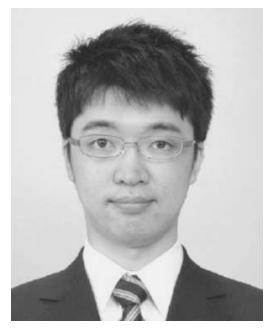

Junichi Takayama was born in Japan in 1983. $\mathrm{He}$ received the B.Eng. degree from Hokkaido University, Sapporo, Japan, in 2007, where he is currently working toward the M.S. degree in the Graduate School of Information Science and Technology, Hokkaido University.

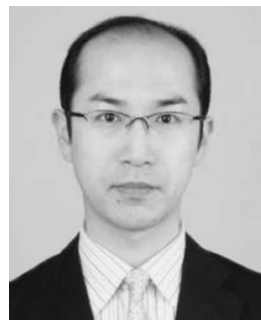

Akinori Oda was born in Japan in 1972. He received the M.E. and Ph.D. degrees in engineering from Hokkaido University, Sapporo, Japan, in 1996 and 2001, respectively.

$\mathrm{He}$ is currently an Assistant Professor with the Department of Engineering Physics, Electronics and Mechanics, Graduate School of Engineering, Nagoya Institute of Technology, Nagoya, Japan.

Dr. Oda is a member of the IEE of Japan, Japan Society of Applied Physics, and Institute of Engineers on Electrical Discharge in Japan. 


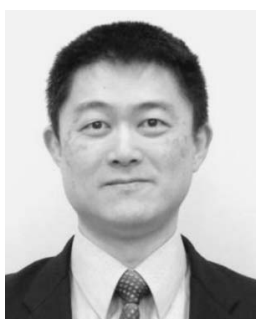

Hirotake Sugawara was born in Japan in 1967. He received the B.E., M.E., and D.E. degrees in electrical engineering from Hokkaido University, Sapporo, Japan, in 1990, 1992, and 1997, respectively.

From 1992 to 1998, he was a Research Associate with the Department of Electrical Engineering, Hokkaido University, where he was an Associate Professor in 1998. He is currently an Associate Professor with the Division of Electronics for Informatics, Graduate School of Information Science and Technology, Hokkaido University.

Dr. Sugawara is a member of the IEE of Japan and Japan Society of Applied Physics.

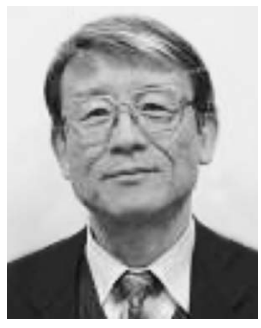

Yosuke Sakai was born in Japan in 1944. He received the M.S. and Ph.D. degrees in engineering from Hokkaido University, Sapporo, Japan, in 1970 and 1973, respectively.

In March 2008, he retired from an education and research position with Hokkaido University after 35 years. He is an Emeritus Professor with Hokkaido University, where he is currently the Director of the Carrier Center. His research interest includes plasma science and electronic conduction in gaseous and liquid dielectrics.

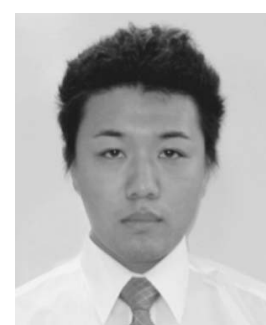

Shinichiro Oke was born in Japan in 1978. He received the M.S. and Ph.D. degrees in engineering from Toyohashi University of Technology, Toyohashi, Japan, in 2003 and 2007, respectively.

$\mathrm{He}$ is currently an Assistant Professor with the Department of Electrical and Electronic Engineering, Toyohashi University of Technology.

Dr. Oke is a member of the IEE of Japan and Japan Solar Energy Society.

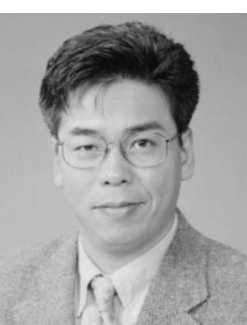

Hirofumi Takikawa (M'06) was born in Japan in 1962. He received the M.S. and Ph.D. degrees in engineering from Toyohashi University of Technology, Toyohashi, Japan, in 1986 and 1992, respectively.

$\mathrm{He}$ is currently a Professor with the Department of Electrical and Electronic Engineering, Toyohashi University of Technology.

Prof. Takikawa is a member of the IEE of Japan and Japan Society of Applied Physics. 